\title{
AKTIVITAS ANTIBAKTERI EKSTRAK DAUN KECAPI (Sandoricum koetjape Merr.)
}

\author{
Pindo Hardika P.A.N, Aditya Fridayanti, Laode Rijai \\ Laboratorium Penelitian dan Pengembangan FARMAKA TROPIS, Fakultas Farmasi, Universitas Mulawarman, \\ Samarinda, Kalimantan Timur \\ email: $\underline{\text { mome.dika@yahoo.com }}$
}

\begin{abstract}
A research has been conducted on the antibacterial activity of the santol leaves extract (S.koetjape Merr.) against S.aureus and E.coli. The santol leaves extracts were prepared by maceration used methanol as solvent and the methanol extract was then fractionated. The antibacterial activity was determined by measured the diameter of inhibition zones in difusi method. The result showed that santol leaves extracts and fractions has antibacterial activity against S.aureus and E.coli. The effective concentration as an antibacterial of methanol extracts is at 10\%, and of n-hexane fractions is at $5 \%$.
\end{abstract}

Keywords : S.koetjape Merr, Santol leaves, Antibacteria

\begin{abstract}
Abstrak
Telah dilakukan penelitian uji aktivitas antibakteri ekstrak daun kecapi (S.koetjape Merr.) terhadap S.aureus dan E.coli. Ekstrak daun kecapi dibuat secara maserasi dengan pelarut metanol, lalu difraksinasi. Uji aktivitas antibakteri ekstrak daun kecapi diukur berdasarkan luas daerah zoa bunuh pertumbuhan bakteri dengan metode difusi agar. Hasil uji menunjukkan bahwa ekstrak dan fraksi daun kecapi memiliki aktivitas antibakteri terhadap bakteri S.aureus dan E.coli. Konsentrasi efektif antibakteri ekstrak metanol adalah $10 \%$ dan fraksi $n$-heksana adalah $5 \%$.
\end{abstract}

Kata Kunci : S.koetjape Merr, Daun Kecapi, Antibakteri

\section{PENDAHULUAN}

Sejak ratusan tahun yang lalu, nenek moyang bangsa kita telah terkenal pandai meracik jamu dan obat-obatan tradisional. Beragam jenis tumbuhan obat, akar-akaran, dan bahan-bahan alamiah lainnya diracik sebagai ramuan jamu untuk menyembuhkan berbagai penyakit. Ramuan-ramuan itu digunakan pula untuk menjaga kondisi badan agar tetap sehat, mencegah penyakit, dan sebagian untuk mempercantik diri. Kemahiran meracik bahan-bahan itu diwariskan oleh nenek moyang kita secara turun-temurun, dari satu generasi ke generasi berikutnya, hingga ke zaman kita sekarang (Juliantina, 2008).

Tumbuhan obat sudah sangat populer di kalangan masyarakat Indonesia sebagai bahan obat tradisional, dan merupakan sarana penunjang kesehatan masyarakat turun-temurun, jauh sebelum pelayanan kesehatan formal dan obat-obatan modern menyentuh lapisan masyarakat. Pemanfaatan tumbuhan obat di Indonesia secara tradisional semakin disukai karena 
efek samping lebih kecil dari obat yang dibuat secara sintesis. Mahalnya obat sintesis membuat masyarakat beralih ke tumbuhan obat. Penggunaan tumbuhan obat di masyarakat terutama untuk mencegah penyakit, menjaga kesegaran tubuh maupun mengobati penyakit (Juliantina, 2008).

Salah satu tumbuhan yang berkhasiat obat adalah tumbuhan kecapi (S.koetjape Merr.). Buah kecapi biasanya dimanfaatkan sebagai bahan makanan, seperti selai, manisan dan sirup. Daun kecapi banyak dimanfaatkan dalam pengobatan tradisional sebagai obat diare, obat mulas, dan obat untuk infeksi kulit seperti bisul (Tinggen, 2000). Penyakitpenyakit yang dapat disembuhkan oleh tumbuhan kecapi pada umumnya disebabkan infeksi oleh bakteri, sehingga diperkirakan di dalam tumbuhan kecapi terkandung suatu senyawa yang mempunyai aktivitas antibakteri (Suartini, 2006). Karena adanya keinginan untuk mengetahui pengaruh efek dari tumbuhan yang berkhasiat sebagai obat tradisional, serta menjaga kelestarian tumbuhan kecapi dan mengembangkan tumbuhan obat di Kalimantan Timur maka penulis tertarik melakukan penelitian mengenai potensi ekstrak daun kecapi (S.koetjape Merr.)sebagai antibakteri.

Penelitian ini bertujuan untuk mengetahui aktivitas antibakteri ekstrak daun kecapi terhadap bakteri S.aureus dan E.coli.

\section{METODE PENELITIAN}

\section{Bahan}

Bahan yang diteliti adalah simplisia daun kecapi (S.koetjapi Merr.). Pelarut metanol digunakan untuk proses ekstraksi dan fraksinasi. Pelarut $n$-heksana, etil asetat, $n$ - butanol digunakan untuk fraksinasi caircair. Aquades, paper disc, kertas label, biakan bakteri uji S.aureus dan E.coli, Nacl 0,9\%, dan Nutrient Agar (NA) digunakan sebagai media pertumbuhan bakteri uji.

\section{Alat}

Alat-alat yang digunakan pada penelitian adalah neraca analitik (Precisa XB 4200 $C^{\circledR}$, Precisa XT $\left.220 A^{\circledR}\right)$, toples, botol selai, batang pengaduk, gelas kimia $\left(\right.$ Pyrex $\left.^{\circledR}\right)$, gelas ukur $\left(\right.$ Pyrex $\left.{ }^{\circledR}\right)$, labu ukur $\left(\right.$ Pyrex $\left.{ }^{\circledR}\right)$, erlenmeyer (Pyrex $\left.{ }^{\circledR}\right)$, tabung pereaksi $\left(\right.$ Pyre $\left.^{\circledR}\right)$, botol timbang, spoit, corong pisah, rotary evaporator $\left(\right.$ Heidolph $\left.^{\circledR}\right)$, pipet tetes, pipet volume $\left(\right.$ Pyrex $\left.^{B}\right)$, cawan porselin, kaca arloji, spatula, pinset, rak tabuk reaksi, aluminium foil, botol vial, penangas air, kertas saring Whatman, pompa vakum, laminar air flow (LAF), ose, mikrometer sekrup, lampu spritus, autoklaf, inkubator, oven.

\section{Prosedur Pengujian Antibakteri}

Pengujian aktivitas anibakteri daun kecapi dilakukan dengan menggunakan metode difusi agar. Diinokulasikan suspensi bakteri uji pada medium NA di dalam botol pengencer dan dihomogenkan. Selanjutnya medium yang telah diinokulasi tersebut dimasukkan ke dalam cawan petri steril dengan cara aseptis di dalam Laminar Air Flow. Dicelupkan paperdisc ke dalam masing-masing variasi konsentrasi ekstrak dan fraksi kemudian paperdisc diletakkan diatas permukaan agar, lalu diinkubasi di dalam inkubator selama 24 jam pada suhu $37{ }^{\circ} \mathrm{C}$. Diamati zona hambat yang terbentuk dan diukur daerah hambatan dengan menggunakan mikrometer skrup. Selanjutnya dibandingkan hasil daya hambat yang terbentuk antara sampel dengan kontrol negatif. 


\section{HASIL DAN PEMBAHASAN}

Pengujian aktivitas antibakteri ekstrak metanol daun kecapi, digunakan 5 variasi konsentrasi yaitu 5\%, 7,5\%, 10\%, 12,5\%, dan $15 \%$. Pada 5 variasi konsentrasi tersebut didapatkan aktivitas antibakteri daun kecapi yang menggunakan metode difusi agar dan hasil pengukuran rata-rata diameter zona bunuh ekstrak metanol daun kecapi (S.koetjape Merr.) terhadap S.aureus dan E.coli dapat dilihat pada Gambar 1 dan Tabel 1.

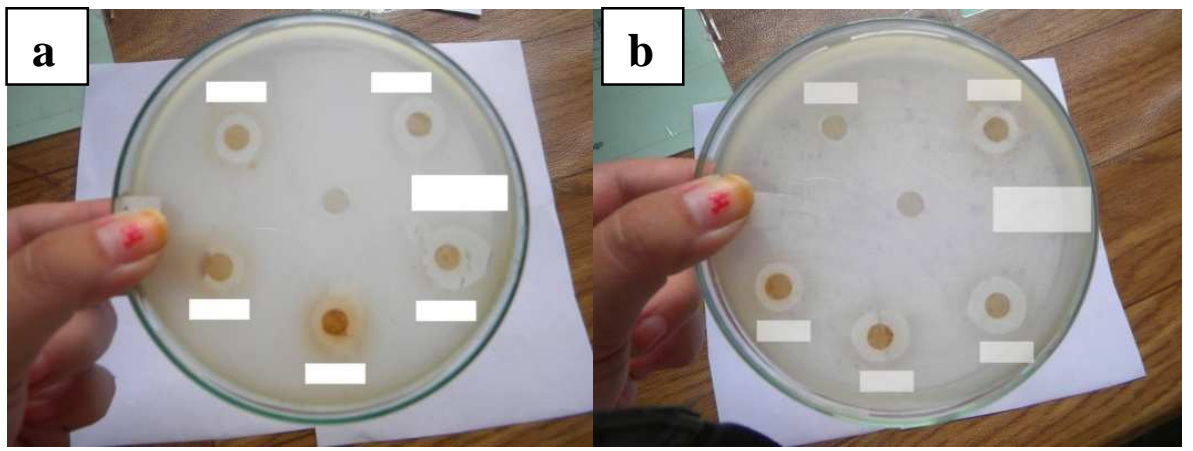

Gambar 1. Uji Aktivitas antibakteri ekstrak metanol daun kecapi terhadap bakteri S.aureus dan E.coli Keterangan:

a: Ekstrak metanol terhadap bakteri S.aureus

b: Ekstrak metanol terhadap bakteri E.coli

Tabel 1. Hasil pengukuran rata-rata diameter zona bunuh ekstrak metanol daun kecapi terhadap bakteri S.aureus dan E.coli

\begin{tabular}{cccc}
\hline Bakteri Uji & Konsentrasi (\%) & Rerata Diameter Zona Bening (mm) & Kontrol Negatif (air) \\
\hline S.aureus & 5 & 8,84 & 0 \\
& 7,5 & 9,49 & 0 \\
& 10 & 14,22 & 0 \\
& 12,5 & 10,76 & 0 \\
& 15 & 10,22 & 0 \\
\hline E.coli & 5 & 9,62 & 0 \\
& 7,5 & 11,69 & 0 \\
& 10 & 14,51 & 0 \\
& 12,5 & 11,70 & 0 \\
& 15 & 10,28 & 0 \\
\hline
\end{tabular}

Grafik aktivitas antibakteri ekstrak metanol daun kecapi terhadap bakteri S.aureus dan E.coli dapat dilihat pada Gambar 2.

Ekstrak metanol daun kecapi mampu memberikan aktivitas antibakteri terhadap bakteri S.aureus dan E.coli yang ditunjukkan dengan terbentuknya zona bening sebagai zona bunuh bakteri, ini terlihat pada gambar, tabel dan kenaikan grafik diatas. Peningkatan aktivitas antibakteri pada ekstrak metanol daun kecapi ditunjukkan pada konsentrasi 10\% atau merupakan konsentrasi efektif dari ekstrak metanol daun kecapi yaitu konsentrasi terkecil yang paling baik memberikan aktivitas antibakteri karna dapat berdifusi dengan baik kedalam media agar pada bakteri S.aureus dan E.coli. Pada konsentrasi $12,5 \%$ dan $15 \%$ aktivitas antibakteri mengalami penurunan. Penurunan aktivitas antibakteri ini diduga adanya pengaruh dari viskositas larutan ekstrak yang tinggi akibat peningkatan konsentrasi, sehingga ekstrak belum mampu untuk berdifusi dengan baik 
kedalam media agar. Sedangkan untuk kontrol negatif tidak memberikan aktivitas antibakteri, hal ini terlihat dari tidak terbentuknya zona bening. Tujuan dari penggunan kontrol negatif itu sendiri adalah untuk memastikan zona bening atau zona bunuh yang terbentuk bukan merupakan pengaruh dari pelarut metanol yang digunakan untuk melarutkan ekstrak, tetapi murni dari senyawa aktif yang terkandung di dalam ekstrak metanol daun kecapi.

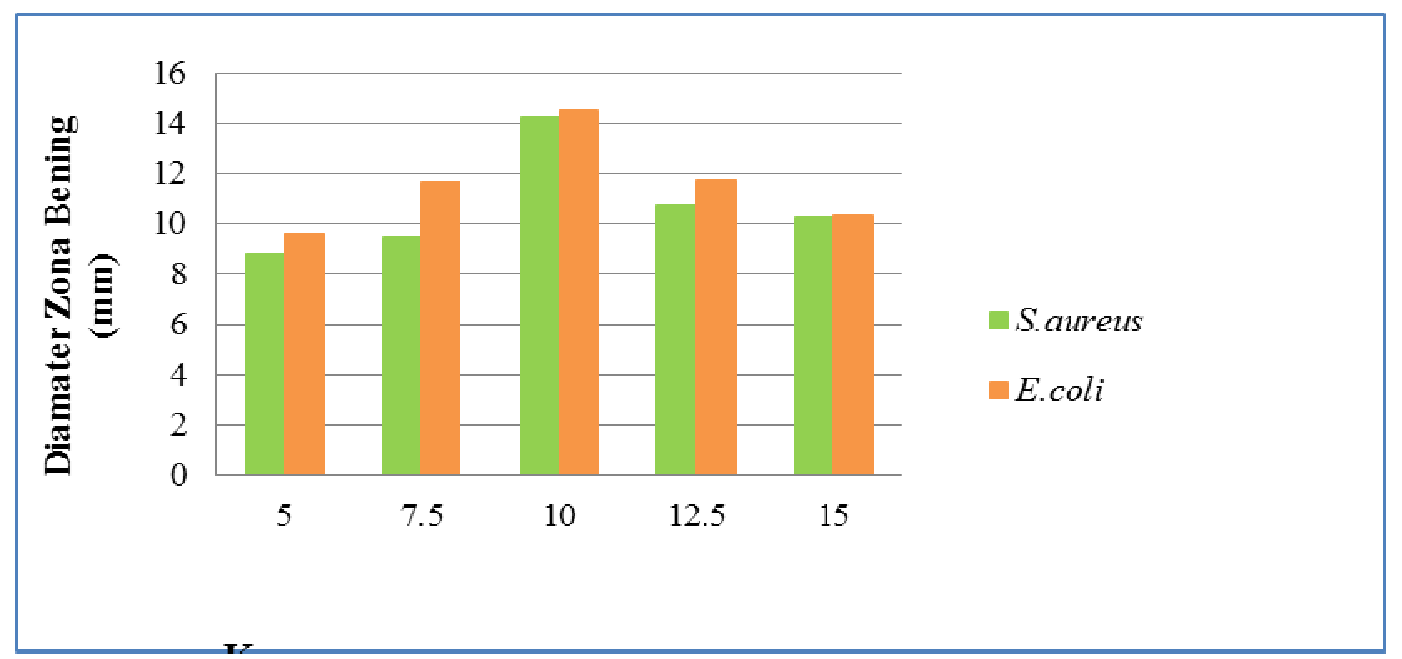

Gambar 2. Grafik Aktivitas Antibakteri Ekstrak Metanol Daun Kecapi terhadap Bakteri S.aureus dan E.coli

Pada pengujian aktivitas antibakteri fraksi $n$-heksana daun kecapi, digunakan 5 variasi konsentrasi yaitu 1\%, 3\%, 5\%, 7\%, dan 9\%. Aktivitas fraksi $n$-heksana daun kecapi membutuhkan konsentrasi yang lebih kecil dibandingkan dengan ekstrak metanol. Hal ini dikarenakan ekstrak hasil fraksinasi sudah terpisah sesuai kelarutannya di dalam masing-masing pelarut fraksi sehingga diduga mampu meningkatkan aktivitas antibakterinya. Hasil pengujian aktivitas antibakteri fraksi $n$-heksana daun kecapi (S.koetjape Merr.) dan hasil pengukuran rata-rata diameter zona bunuh fraksi $n$-heksana daun kecapi (S.koetjape Merr.) terhadap S.aureus dan E.coli dapat dilihat pada Gambar 3 dan Tabel 2.
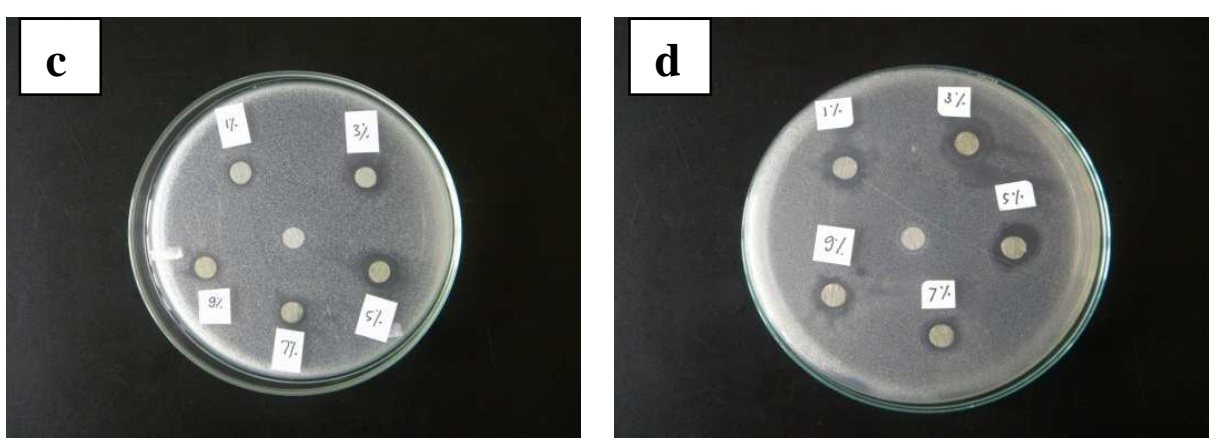

Gambar 3. Uji Aktivitas antibakteri fraksi n-eksana daun kecapi terhadap bakteri S.aureus dan E.coli Keterangan:

c: Fraksi n-heksana terhadap bakteri S.aureus

d: Fraksi n-heksana terhadap bakteri E.coli 
Aktivitas Antibakteri Ekstrak Daun Kecapi (Sandoricum Koetjape Merr.)

Tabel 2. Hasil pengukuran rata-rata diameter zona bunuh fraksi n-heksana daun kecapi terhadap bakteri S.aureus dan E.coli

\begin{tabular}{cccc}
\hline Bakteri Uji & Konsentrasi $(\%)$ & Rerata Diameter Zona Bening $(\mathbf{m m})$ & Kontrol Negatif (air) \\
\hline S.aureus & 1 & 8,34 & 0 \\
& 3 & 9,49 & 0 \\
5 & 11,57 & 0 \\
& 7 & 9,74 & 0 \\
& 9 & 8,92 & 0 \\
\hline E.coli & 1 & 7,52 & 0 \\
& 3 & 8,89 & 0 \\
& 5 & 12,41 & 0 \\
& 7 & 8,19 & 0 \\
& 9 & 6,72 & 0 \\
\hline
\end{tabular}

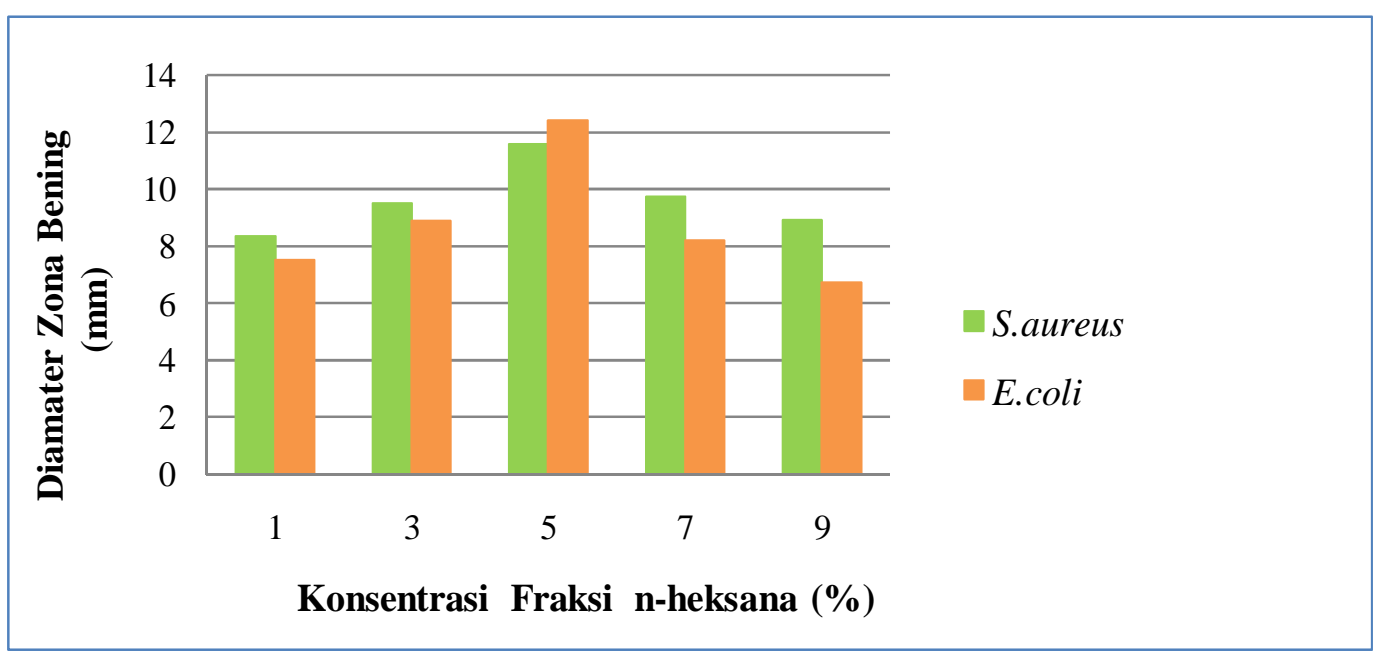

Gambar 4. Grafik Aktivitas Antibakteri Fraksi n-heksana Daun Kecapi terhadap Bakteri S.aureus dan E.coli

Grafik aktivitas antibakteri fraksi $n$ heksana daun kecapi terhadap bakteri S.aureus dan E.coli dapat dilihat pada Gambar 4.

Fraksi $n$-heksana daun kecapi mampu memberikan aktivitas antibakteri terhadap bakteri S.aureus dan E.coli yang ditunjukkan dengan terbentuknya zona bening sebagai zona bunuh bakteri, ini terlihat pada tabel dan kenaikan grafik diatas. Peningkatan aktivitas antibakteri pada fraksi $n$-heksana daun kecapi ditunjukkan pada konsentrasi 5\%. Pada konsentrasi $7 \%$ dan $9 \%$ aktivitas antibakteri mengalami penurunan. Penurunan aktivitas antibakteri ini diduga adanya pengaruh dari viskositas larutan ekstrak yang tinggi akibat peningkatan konsentrasi, sehingga ekstrak belum mampu untuk berdifusi dengan baik kedalam media agar.

\section{KESIMPULAN}

Ekstrak metanol dan fraksi n-heksana daun kecapi (S.koetjape Merr.) memiliki aktivitas sebagai antibakteri terhadap bakteri S.aureus dan E.coli. 


\section{SARAN}

1. Dapat dilakukan penelitian lebih lanjut tentang pengaruh ekstrak daun kecapi terhadap antijamur.

2. Dapat dilakukan pengujian terhadap bagian tumbuhan yang lain seperti batang, buah dan akar.

3. Dapat dilakukan pengujian isolasi senyawa yang aktif dari daun kecapi untuk penelitian selanjutnya.

\section{UCAPAN TERIMA KASIH}

Dalam kesempatan ini peneliti menyampaikan terima kasih dengan ini kepada staf laboran yang telah membantu sehingga terselesaikannya artikel ilmiah ini.

\section{DAFTAR PUSTAKA}

1. Djide, N. \& Sartini. 2008. Analisis Mikrobiologi Farmasi. Lephas; Makasar

2. Juliantina, F. R.; Ayu, D. C. M.; \& Nirwani, B. 2008. Manfaat Sirih Merah (Piper crocatum) sebagai Agen Antibakterial Terhadap Bakteri Gram Positif dan Gram Negatif. Jurnal Kedokteran dan Kesehatan Indonesia.

3. Suartini, N. M. 2006. Skrining, Isolasi, dan Identifikasi Senyawa Antibakteri dalam Tumbuhan Berkhasiat Sebagai Obat Sakit perut yang Tercatat dalam Usada Taru Premana. Universitas Udayana; Bali

4. Tinggen, I.N. 2000, Taru Premara, Pustaka Leluhur Eka Cipta; Singaraja 